\title{
CREATIVE STRATEGIES TO SUPPORT STUDENT LEARNING THROUGH REFLECTION
}

\author{
G. H. van Rensburg \\ Department of Health Studies \\ University of South Africa \\ Pretoria, South Africa \\ e-mail: vrensgh@unisa.ac.za
}

\section{Y. Botma}

School of Nursing

University of the Free State

Bloemfontein, South Africa

e-mail: botmay@ufs.ac.za

\section{T. Heyns*}

e-mail: tanya.heyns@up.ac.za

\section{M. Coetzee*}

e-mail: isabel.coetzee@up.ac.za

*Department of Nursing Science

University of Pretoria

Pretoria, South Africa

\section{ABSTRACT}

Reflective practice has become a key attribute of promoting quality teaching and learning. Learning is an active process and include reflective writing, visualising and verbalising to promote critical thinking. In our experience most often than not superficial reflective writing is used. We explored the design of opportunities for students to engage in critical reflection. Theoretical data were obtained through in-depth exploration of the literature to allow contextualisation while arguing a case. A qualitative approach was used. Judgements were not made about the measured quality of reported findings, but on the relevance of reflective strategies to support students, enhance critical reflection and transform practice. Combined with narration and dialogue, reflection can bridge the gap between theoretical ideals and realities of the practice context. Four reflective activities have been identified that could be used to engage students in critical reflection.

Keywords: action learning, concept mapping, critical incident, reflection, reflective strategies, storytelling, student support 


\section{INTRODUCTION}

Reflective practice is a key component of teaching and learning (Maree and Van Rensburg 2013; O'Farrell and Fitzmaurice 2013; Mantzoukas 2007), valuable for lifelong learning (Ryan and Ryan 2013) and an essential attribute for professional competency (Moon 1999; Boud, Keogh and Walker 1985; Argyris and Schön 1974). Reflection involves an understanding of responses, beliefs and premises by both the educator and student to enable purposeful integration of a reflective approach to learning. Enabling students through examining and exploring their responses, beliefs and premises, students are enabled to connect with and integrate new understanding of their experiences, which results in new learning (Mann, Gordon and MacLeod 2009; Mantzoukas 2007). The value of reflective learning is widely recognised in improving student learning and achievement (Ryan and Ryan 2013), recognising the importance of the epistemological shift to include reflection into teaching and learning practices.

An epistemological shift to include reflection into teaching and learning practice means changing from a positivistic "knowing that" to a reflective "knowing how" perspective. The concept of reflection therefore departs from the notion that one should focus on "what is" and aims to enhance practice from that starting point (Kane, Sandretto and Heath 2004). Reflection abandons the notion that there is a single and one definite right answer to professional or academic situations. Hills and Watson (2011) describe reflection as an element in their emancipatory relational pedagogical framework. These authors maintain that students must be provided with actual experience of discovering reflection as actions. In practice then, activities to reflect become an important aspect of learning. A reflective epistemology in higher education further involves processes of facilitation where students respond and take action through the systematic exploration and interpretation of unique situations and implement emergent ideas to resolve individual and unique learning opportunities. Hence, a core element of reflective epistemology is that it is student-centred in that students' experiences and perceptions are important in the development and positioning of knowledge (Hofer 2017; Mantzoukas 2007).

As a student-support strategy reflection requires deliberate planning and active participation of the student. The educator adopts a facilitator approach that is characterised by 1) being present but not to prominent, 2) provide a balance in the support by giving responsibility (to students) and having control (of the activity and learning) (Van Beveren et al. 2018) and 3) creating a space for reflective practice to flourish.

By creating a safe non-judgemental space, educators support students (Van Beveren et al. 
2018), giving them an opportunity to become more independent in their learning. Reflection could create a feeling of discomfort when confronted with situations where students must "unlearn" previously acquired learning practices. Therefore, by being creative and flexible, educators allow for and inspires mindful learning and personal growth (Botha 2017; Jonassen 1995). Using creative activities is core to the success of reflection.

Ryan and Ryan (2013) suggest that reflection should be much more than only reflective writing, which is often superficial. It is not only of relevance what one reflects on or why one reflects but how one reflects. The "how" which is evident by different reflective activities could be regarded as a form of "triangulation" of learning experiences of students to improve their own learning and academic achievement. In adult learning one tends to believe that students whose intelligent strengths lie in more creative activities could be accommodated through alternative reflective activities of self-expression. Often reflective journaling or diary writing facilitates the initial skills required for reflection, which focuses on individual learning. Reflective practices are much more than that. The ability to demonstrate problem solving and critical thinking is not automatically present in reflective journaling (Newton 2004) and therefore should incorporate reflective activities, which may not only contribute to critical and meaningful reflection but also focuses on learning from and with each other. In a study conducted by Naicker (2014) the results showed that the most common activities used to promote reflective learning by students are small group discussions (83\%), role playing (69\%), problem solving $(79 \%)$ and case studies $(71 \%)$. The respondents $(60 \%)$ also preferred simulation and presentations activities but to a lesser degree.

The three levels of reflection that one has to consider when using reflective activities as a teaching and student support strategy are descriptive, dialogic and critical reflection (Sherwood and Horton-Deutsch 2012). Descriptive reflection is a conscious effort to think about an event or activity that allows one to consider what was positive or challenging and if necessary, how could one have acted differently. This level of reflection is regarded as a starting point where making sense of the event remains a description of or report on that event (Botma et al. 2015; Roffey-Barentson and Malthouse 2009). Dialogic reflection is stepping back from and making meaning of the description of the event itself to include the possible reasons for why things happened and validating the contributing factors to the event (Botma et al. 2015; Roffey-Barentson and Malthouse 2009). Critical reflection refers to when one takes a more evaluative position and considers a range of viewpoints to understand what happened and why it happened (Roffey-Barentson and Malthouse 2009). Critical reflectors have multiple ways of knowing whereby new perspectives inform future actions and practices (Ryan and Ryan 2013; Roffey-Barentson and Malthouse 2009). 
The following question prompted the authors to embark on a focused literature review of reflection as a student-support strategy, namely: What reflective activities could be used to support students to become critical reflectors? This article focuses on how the choice of reflective activities could contribute to the educational value of the reflective processes.

\section{METHODOLOGY}

A literature search was conducted using a university online library data base. The search terms used were: reflective activities, reflective student support strategies and reflective teaching practices. Sources from 2000 onwards were searched with the exception of two seminal. sources. The results were limited to English language articles and other relevant sources such as books and dissertations. The search resulted in the use of both primary and secondary sources. Sources suggesting reflective journaling were not included based on the statements by Epp (2008), Naicker (2014) and Ryan and Ryan (2013) that reflection by means of journaling is often times superficial.

The authors reviewed the relevant literature in order to describe the nature of learning experiences as well as the role of the underlying structures and conditions of reflective activities as student-support strategies. Theoretical data were obtained through in-depth exploration of the relevant literature to allow contextualisation while arguing a case, and to identify a niche to be occupied by this research (Machi and McEvoy 2016). A qualitative approach was used where judgements were not made about the measured quality of reported findings in the literature but rather the relevance to the phenomenon of reflective activities as student-support strategies in enhancing critical reflection and transformation of practice. The ultimate epistemological criterion was therefore pragmatic in that the review was done in order to suggest transformation and change in the "world" of the teaching and learning environment (Polit and Beck 2017). The review process was a permutation of blending/synthesising data, describing transformational practices in the teaching and learning environment and providing specific explanations related to perceived meanings (Walsh and Downe 2005).

Using inductive processes explanations were built around reflective practices and those that could enhance the teaching and learning process. Through a process of synthesis of studies by different researchers, four reflective activities were acknowledged and selected for further analysis. The reflective activities were identified as suitable to stimulate students with different cognitive styles and personal strengths and talents.

The most important ethical consideration was related to the recognition of authorship and the prevention of plagiarism. This was ensured by referring to the authors as their work was quoted or used in the article and by being true to what was presented in the literature. 
Furthermore, the authors of this article have a true interest in improving practice in terms of education and practice.

The criteria for excellent qualitative research suggested by Tracy (2010) were considered to explain the rigour of the research. The article addresses a worthy topic that is relevant, timely and interesting. Repeated literature searches using various search engines and data bases were conducted by the authors and subject librarians. The authors were transparent about the methods and limitations of the study. The content of this article is transferable to multiple professions and education contexts. The practical application of the proposed reflective activities may move educators and practitioners to critically reflect and transform practice.

\section{FINDINGS}

People reflect in many different ways. Reflective activities and the context within which it takes place result in a high degree of complexity in understanding and practising reflection (Hickson 2011). From the focused literature review four reflective activities, namely storytelling, concept mapping, critical incidents and action learning, have been identified which could be used as student support strategies to encourage a transition from descriptive to critical reflection.

\section{Storytelling}

Storytelling is a fundamental part of life and there is an increasing acknowledgement of the value thereof in education (McAllister 2015). Storytelling is a form of narrative information that helps us to articulate and understand ourselves. It enables us to bring life experiences into context and, in doing so, bring about learning (Phillips, Bassell and Fillmore 2017). Stories could include life stories, autobiographies, personal histories or social practices. Through reflection, stories create a unique bridge from experiences to an essential mode of personal growth. It typically consists of a beginning, middle and an end that is told from one or more perspectives. The advantages are that personal stories are brought to the fore, elucidating the complexities of a situation, story or a theme with a human side to it. Through storytelling, new knowledge is formed that can be applied professionally (Phillips et al. 2017; Murphy, Halton and Dempsey 2008). As a reflective technique storytelling or narration further has the ability to present the human side of education and demonstrate some of the deeply personal and individual stories and becomes both a student-support strategy and a learning activity (Jones 2011). Criticism of storytelling and narration is that it requires operating at a personal level, yet it is used as a cognitive construct (O'Farrell and Fitzmaurice 2013). However, this criticism in itself stimulates both cognitive and affective learning processes. 
Stories can be formal or informal. Processes involved in storytelling as a teaching and learning activity involve constructing a narrative demonstration and then asking the following questions:

- What happened and why?

- What was expected to happen?

- What does it mean?

- How does the event affect practice?

Storytelling as a reflective activity in student support and as a learning activity encourages meaningful communication and critical thinking and should not be without structure. As with other reflective activities it could be described as a deliberate cognitive and affective exploration of experiences with the purpose to learn from these experiences. Facilitated discussions are held where narratives or experiences are shared in small groups (Forneris and Peden-McAlphine 2007). The experiences are expressed in story form, either by the educator or the students themselves. Haphazard reflection through storytelling could lead to frustration, fatigue and stress (Jones 2011). Therefore, a constructive approach is necessary to lead to practical outcomes that are focused on sustaining and strengthening student support in the teaching and learning environment.

\section{Concept mapping}

The concept map is a visual presentation of meaningful relationships between concepts in the form of propositions (two or more topics linked by verbs that describe the relationship between them). Although not always the case, a concept map could be presented in the form of a collage that creates an avenue for expression in a creative manner. The advantage of such a collage is that it does not require artistic characteristics in producing it, but rather a mix of surrender and initiative. Concept maps represent an individual student's own interpretation of ideas in a diagrammatic form, allowing them to organise information based on their knowledge, insight, understanding and experiences within a given context. Concept mapping is sometimes seen as a release of inhibitions and inflexibility that results in responsiveness to what is taking place in the here and now (Basavanthappa 2009; Bressington et al. 2018).

Drawing the concept map requires critical thinking about the topic and related concepts. Questions that one should ask when reflecting in this manner are: 
- Where is the most general topic/concept? This is normally either at the top or in the middle.

- Are the relationships between concepts indicated?

- Are there any concepts or relationships missing?

- Are there any contradictions in the concept map?

- $\quad$ Does the concept map portray your current knowledge, values or beliefs?

- What are the assumptions that underlie the shape or format of the concept map?

- Do the links actually portray your experiences or the cause and effect relationship? (Kuit and Reay 2001).

The organisational patterns that appear in a concept map are visual graphics that represent how the individual thinks about the topic or to create meaning to experiences and a specific area of knowledge. It encourages highly divergent lateral and creative thinking through the schematic processes as well as opportunities for convergent thinking in that it stimulates new ideas. Reflecting through visual activities assists in the ability to analyse complex situations, recognise subtleties in problems and offer opportunities for solutions to problems (Killen 2007). As a reflective activity or technique it draws on the same process as reflective journaling in that it entails processes of self-regulation and self-confrontation. The concept map is a mirror and an external representation of thinking and reflecting in the form of a map.

\section{Critical incidents}

One of the first definitions of a critical incident was by Flanagan $(1954,338)$ who stated that "an incident is critical if it makes a `significant contribution, either positively or negatively to the general aim of the activity". Critical incident is a well proven qualitative research approach that offers a practical step-by-step way to collecting and analysing information pertaining to human activity and its significance to the people involved (Hudges 2007). Radford (2006) maintains that critical incidents lend themselves to qualitative investigation, based on the fact that critical incidents provide authentic foci and prompt participant recall as well as promote understanding of a specific phenomenon. Reflecting is a way to explore, explain, consider, justify and learn from incidents that occur in day-to-day practice, thus becoming a suitable approach to deal with challenges in everyday practice. Hudges (2012) is of the opinion that critical incidents offer a convincing focus for exploring research pertaining to human experiences.

Furthermore, a critical incident is defined as a specific technique in reflection where 
students are asked to describe and analyse a particular meaningful incident they have experienced or observed in the learning environment (Billings and Halstead 2012). Using a critical incident as a reflective activity provides a deeper level of reflection based on the fact that it goes beyond a detailed description of an event (Griffen 2003). The elements of the process when using critical incidents during reflection may include:

- Identify the most obvious active failures

- $\quad$ Framing the problem

- $\quad$ Defining the problem (what, how, why) (Seckler-Walker and Taylor-Adams 2001)

Using critical incidents gives an opportunity for the analysis of and reflection on the meaning of the event/incident. The steps used in the critical incident technique as a reflective activity entail the establishment of the purpose of the activity, collecting data, analysing the data, interpreting the findings and reflecting continuously through all phases to support learning. Reflection takes place "forward" in terms of the value of the critical incident and the critical incident technique in the teaching and learning environment but also "backwards" to identify strengths and limitations of the critical incident as a learning opportunity and support strategy.

\section{Action learning}

Learning is regarded as both active and reflective processes. Both these processes should be accommodated in an optimal learning environment where sufficient time for learning is provided (Smith and Stitts 2013). Action learning is a learning strategy that embraces collaborative and social processes that accelerate the creation of new knowledge through action and reflection - where action and reflection are regarded as parallel processes (Park et al. 2013). Using action learning as a reflective activity provides students with opportunities to learn effectively from and with each other while they are tackling problems through experience, critical insight and judgement (Coghlan 2013).

The educator has the responsibility to set the stage for learning through reflection by using context-sensitive facilitation skills and open-ended questioning techniques throughout the continuous action learning process (Brook and Aspinwall 2013). The reflective process is initiated by a provocative central question. On the basis of the question students will start to seek clarification and resolve the challenge. Asking questions promotes reflection and invigorates an inquiring mind set, thinking, learning and action which are then followed by results (Adams 2010). The six steps involved in the action learning process include problem 
identification, planning, action, observation, reflection and implications for practice. The lastmentioned three steps are vital components of a critical thinking paradigm (Smith and Stitts 2013).

Action learning has advantages for the individual, the group and the practice. On the individual level action learning uses a collaborative approach where learning is deliberate and students are able to share knowledge and learn from each other by reflecting on a specific topic or activity. Developing capabilities through interaction with group members will improve decision-making- and problem-solving skills and result in the re-construction of knowledge (Adams 2010). Through reflection of experiences action learning supports students in developing and facilitating collaborative leadership skills that will bring rapid change to the practice environment (Pennington et al. 2013). Students are motivated to take ownership of the learning process, which enhances the transfer of learning to practice (Shurville and Rospigliosi 2009). In the group, action learning encourages working collaboratively and reflecting critically about challenges identified in practice. This interaction between group members enhances the self-confidence of individuals because of the feedback and reflection that takes place in the group (Smith and Stitts 2013). The group benefits from action learning as the students engage in feedback and reflection, which in turn raises self-awareness and new insights into the self. Communication is encouraged, trust and commitment to the group members follow with a willingness to engage in question formulation to clarify and solve the challenge faced (Smith and Stitts 2013). Practice is regarded as a diverse environment and action learning focuses on group activities to improve the outcomes in practice. Action learning fosters collaborative networks that enhance innovational culture building practices (Park et al. 2013). Through sharing and re-constructing knowledge students are enabled and empowered to change practice.

During action learning the students learn whilst focusing and reflecting on real world challenges. Students meet in mutually supportive small groups or "sets" (three to seven members) to actively engage in learning. The sets operate to agreed ground rules and with the help of an educator address a problem that promotes engagement of their understanding making their knowledge more explicit (Edmonstone and MacKenzie 2005).

\section{DISCUSSION}

Reflection provides students an opportunity to think systematically about their actions and responses. Regarded as a change strategy, reflection promotes the spirit of inquiry (Sherwood and Horton-Deutsch 2012). The change strategy incorporates experiential learning and a space is created to think about what one knows, one's emotions as well as what one's values and 
believes are and within a specific situation and context (Sherwood and Horton-Deutsch 2012). There are different perspectives and choices of reflective activities that can be used to support students in the teaching and learning environment.

Using creative reflective activities as a cognitive-support measure enable students to reach the outcome of critical reflection. The support that students receive before and during reflective activities, as well as the selection of the reflective activities, determines the level of reflection (Dyment and O'Connell 2011; Freshwater, Taylor and Sherwood 2008). As reflective practitioners, students bring along intra- and interpersonal dimensions, where intrapersonal dimensions determine the level of motivation, self-efficacy and locus of control and interpersonal dimensions emphasise the different aspects and levels of relationships (Howatson-Jones 2016; Stage and Hossler 2000). Carey (2013) explains the relationships as engagements or student participation that results in a common focus on learning activities that extends beyond academic performance. The notion of participation thus requires that engagement takes place from both a process point of view as well as through an intrinsic approach. Educators should create psychological safe spaces where students can authentically connect their ideas with those of others and become critical reflectors (Howatson-Jones 2016). Critical reflectors become part of the decision-making processes, have high motivation levels and contribute to practice enhancement through innovation and transformation. Reflective activities should therefore be part of an integrated network of activities that cultivate deep learning and transformative practice (Mann, Gordon and MacLeod 2009; Sherwood and Horton-Deutsch 2012).

Understanding the complexities in student support requires critical reflective educators or facilitators of reflection (Sherwood and Horton-Deutsch 2012). When becoming involved in preparing students to the highest academic levels, one should continuously face the question on how to offer optimal cognitive support to students. Educators as the facilitators of reflective activities become the link between the student and learning in that they expand student support strategies to meet the needs of diverse student population. True student support results in positive student experiences with high levels of satisfaction and successful experimentation with newly constructed knowledge.

Student support is associated with, amongst other things, learning activities and processes that are associated with personal change and empowerment as an aspiration to improve oneself in order to transform practice. The context in which learning opportunities are provided and student support is rendered, namely the learning climate, should provide connectedness, satisfaction, safety, trust, acceptance and respect (Sherwood and Horton-Deutsch 2012). Learning activities should be structured to introduce students to their "learning edges" by 
challenging them beyond their comfort zone. Educators should create reflective activities in such a manner that students are challenged with variances and divergences in their existing views, behaviour and patterns. During the reflective activity students are guided to determine the relationship between different elements/constructs that elevate the thinking processes to a level of critical thinking. Effective reflective activities result in conclusive statements on what have been learned, what needs to improve, and how to do things differently in similar situations (Ericsson 2007). Schaub-de Jong et al. (2011) define the capability of recognising strengths and weaknesses of the self and the planning of strategies to improve on the weaknesses as selfregulation. Others describe these processes as deliberate practice (Duvivier et al. 2011; Ericsson 2007). According to Kolb's (1984) learning theory students should exhibit active experimentation with new knowledge in class and practice. Active experimentation requires that the educator provides immediate feedback, time for problem solving and evaluation, and opportunities for repeated performance to refine behaviour (Ericsson 2007). Application of new knowledge in practice raises the level of competence of the individual and collectively results in better organisational performance. Therefore, critical reflection becomes essential for successful change and transformative practice.

In order for reflection to be effective in improving teaching and learning it needs commitment in terms of time and intellectual effort. Students may not have the psychological and emotional skills or readiness to engage in creative reflective activities. Educators may not have the skills and knowledge on how to create learning activities for critical reflection. Furthermore the planning of such activities could be time consuming (Harvey et al. 2017) and needs committed educators. Critical reflection may not take place if the activities are not suitable and well-planned.

\section{CONCLUSION}

Traditionally journaling is the most well-known reflective activity and is often superficial and on a descriptive level of reflection. Ideally reflection should be on a critical level in order to enhance deep learning and transform practice. Based on a focused literature review four activities, namely storytelling, concept mapping, critical incident and action learning, were identified that may be used to promote critical reflection.

A strong belief in reflective practice as a student support-strategy brought about this academic debate that acknowledges that reflection might not provide direct and measurable evidence of academic achievement but it may enhance transformative practice, practice improvement and innovation.

Innovative and creative reflective activities are effective ways of developing critical 
thinking and reasoning skills and combined with narration and dialogue, bridge the gap between the theoretical ideals and the realities of the practice context. Enthusiastic educators who are willing to provide a space for reflection, think creatively, explore various activities and commit themselves to innovative practices are, however, necessary to change teaching practices to reach optimal levels of reflection. It is therefore recommended that educators be prepared in various reflective activities and assisted in planning for such. The teaching and learning environment should be adjusted to accommodate these activities in terms of space, time, equipment and interactions. For an educator to teach through reflective activities their patterns of thinking about teaching strategies and student support should include their own practices of reflection and a will to improve practice.

A limitation of this article is that it was not an exhaustive attempt at reviewing the literature on reflective activities that promote critical reflection. Therefore, the activities discussed here are not all-inclusive. However, providing these four examples could stimulate educators to start using creative activities in order to promote critical reflection.

The tacit assumption is that reflection improves student support and learning. No documented studies could be found that provide clear evidence of an association between the proposed reflective activities and student success per se. In addition to exploring educators and students' experiences in using these activities further research could be conducted to investigate whether critical reflection is achieved by means of the proposed activities.

\section{REFERENCES}

Adams, M. 2010. The practical primacy of questions in action learning. Action learning and its applications, present and future. New York: Palgrave Macmillan.

Argyris, C. and D. Schön. 1974. Theory into practice: Increasing professional effectiveness. San Francisco: Jossey Bass.

Basavanthappa, B. T. 2009. Nursing education. Second edition. New Delhi: Jaypee Brothers Medical.

Billings, D. and J. A. Halstead. 2012. Teaching in nursing: A guide for faculty. Fourth edition. St Louis: Mosby/Elsevier/Saunders.

Botma, Y., G. H. van Rensburg, I. M. Coetzee and T. Heyns. 2015. A conceptual framework for educational design at modular level to promote transfer of learning. Innovations in Education and Teaching International 52(5): 499-509.

Botha, C. S. 2017. Using metaphoric body-mapping to encourage reflection on the developing identity of pre-service teachers. South African Journal of Education 37(3): 1-12.

Boud, D., R. Keogh and D. Walker. 1985. Reflection: Turning experience into learning. London: Kogan Page.

Bressington, D. T., W. Wong, K. C. Lam and W. T. Chien, 2018. Concept mapping to promote meaningful learning, help relate theory to practice and improve learning self-efficacy in Asian mental health nursing students: A mixed-methods pilot study. Nurse Education Today 60: 47-55.

Brook, C. and K. Aspinwall. 2013. Creative activities and action learning. Action Learning: Research and Practice. doi.10.1080/14767333.2013.840063. 
Carey, P. 2013. Student as co-producer in a marketised higher education system: A case study of students' experience of participation in curriculum design. Innovations in Education and Teaching International. doi.10.1080/14703297.2013.796714.

Coghlan, D. 2013. Action learning research? Reflections from the colloquium at the Third International Conference on action learning. Action Learning: Research and Practice 10(1): 54-57.

Duvivier, R. J., J. van Dalen, A. M. Muijtjens, V. R. M. P. Moulaert, C. P. M. van der Vleuten and A. J. A. Scherpbier. 2011. The role of deliberate practice in the acquisition of clinical skills. $B M C$ Medical Education 11(c): 101.

Dyment, J. E. and T. S. O'Connell. 2011. Assessing the quality of reflection in student journals: A review of the research. Teaching in Higher Education 16(1): 81-97.

Edmonstone, J. and H. MacKenzie. 2005. Practice development and action learning. Practice Development in Health Care 4(1): 24-32.

Epp, S. 2008. The value of reflective journaling in undergraduate nursing education: Alternative review. International Journal of Nursing Studies 40(9): 1379-1388.

Ericsson, K. A. 2007. An expert-performance perspective of research on medical expertise: The study of clinical performance. Medical Education 41(12): 1124-1130.

Flanagan, J. C. 1954. The critical incident technique. The Psychological Bulletin 51(4): 327-358.

Forneris, S. G. and C. Peden-McAlphine,. 2007. Evaluation of a reflective learning intervention to improve critical thinking in novice nurses. Journal of Advanced Nursing 57(4): 410-421.

Freshwater, D., B. Taylor and G. Sherwood. 2008. International textbook of reflective practice in nursing. Oxford. Sigma ThetaTau International Honor Society of Nursing.

Griffen, M. 2003. Using critical incidents to promote and assess reflective thinking in preservice teachers. Reflective Practice 4(2): 2007-2220.

Harvey, M., M. Baker, A. Semple, K. Lloyd, K. McLachlan, G. Walkerden and V. Fredericks. 2017. Reflection for learning: a holistic approach to disrupting the text. New York: Springer.

Hickson, H. 2011. Critical reflection: Reflecting on learning to be reflective. Reflective Practice 12(6): $829-839$.

Hills, M. and J Watson. 2011. Creating a caring science curriculum: an emancipatory pedagogy for nursing. New York: Springer.

Hofer, B. K. 2017. Shaping the epistemology of teacher practice through reflection and reflexivity. Educational Psychologist 52(4): 299-306.

Howatson-Jones, L. 2016. Reflective practice in Nursing. Third edition. Los Angeles: Sage.

Hudges, H. 2007. Critical incident technique. In Exploring methods in information literacy research, ed. S. Lipu, K. Williamson and A. Loyd, 49-66. Wagga Wagga: Centre for Information Studies. Charles Sturt University.

Hudges, H. 2012. An expanded critical incident approach for exploring information use and learning. Library and Information Research 26(112): 72-95.

Jonassen, D. H. 1995. Supporting communities of learners with technology: A Vision for integrating technology with learning in schools. Educational Technology 35(4): 60-63.

Jones, A. 2011. Seeing the messiness of academic practice: Exploring the work of academics through narratives. International Journal for Academic Development 16: 109-118.

Kane, R., S. Sandretto and C. Heath. 2004. An investigation into excellent tertiary teaching: Emphasising reflective practice. Higher Education 47(3): 283-310.

Killen, R. 2007. Teaching strategies for outcomes-based education. Second edition. Cape Town: Juta.

Kolb, D. A. 1984. Experiential learning: Experience as a source of learning and development. Englewood Cliffs: Prentice-Hall.

Kuit, J. and G. Reay. 2001. Experiences of reflective teaching. Active Learning in Higher Education 
2(2): 128-142.

Machi, L. A. and B. T. McEvoy. 2016. The literature review. Third edition. Corwin: Sage.

Mann, K., J. Gordon and A. MacLeod. 2009. Reflection and reflective practice in health professions education: A systematic review. Advances in Health Sciences Education: Theory and Practice 14(4): 595-621.

Mantzoukas, S. 2007. Reflection and problem/enquiry-based learning: Confluences and contradictions. Reflective Practice 8(2): 241-253.

Maree, C. and G. H. van Rensburg. 2013. Reflective learning in higher education: Application to clinical nursing. African Journal of Physical, Health Education, Recreation and Dance (AJPHERD) Supplement 1: 44-55.

McAllister, M. 2015. Connecting narrative with mental health learning through discussion and analysis of selected contemporary films. International Journal of Mental Health Nursing 24(4): 304-313.

Moon, J. 1999. A handbook of reflective and experiential learning. London: Routledge.

Murphy, M., C. Halton and M. Dempsey. 2008. The transfer of reflective engagement from social work education into the workplace: A study of the value of scaffolded reflection. Irish Educational Studies 27(1): 71-80.

Naicker, K. 2014. The role of educators in facilitating reflective learning in students. Unpublished masters' dissertation. Pretoria: University of South Africa.

Newton, J. 2004. Learning to reflect: A journey. Reflective Practice 5(2): 155-166.

O'Farrell, C. and M. Fitzmaurice. 2013. Academic developers using narrative to support our professional development. Innovations in Education and Teaching International 50(3): 227-237.

Park, S., I. Kang, T. R. Valencic and Y. Cho. 2013. Why are we using action learning and in what context? Action Learning: Research and Practice 10(1): 4-24.

Pennington, K., J. Creswell, T. Snedden, M. Mulhall and N. Ellison. 2013. Ignatian pedagogy: Transforming nursing education. Jesuit Higher Education 2(1): 34-40.

Phillips, C., K. Bassell and R. Fillmore. 2017. Storytelling and reflective pedagogy: Transforming nursing education through faculty development. American Journal of Health Sciences 8(1): 112.

Polit, D. F. and C. T. Beck. 2017. Nursing research: Generating and assessing evidence for nursing practice. Tenth edition. Philadelphia: Lippincott Williams \& Wilkins.

Radford, M. L. 2006. The critical incident technique and qualitative evaluation of the connecting libraries and school project. Library Trends 55(1): 46-64.

Roffey-Barentson, J. and R. Malthouse. 2009. Reflective practice in the lifelong learning sector. Exeter: Learning Matters.

Ryan, M. and M. Ryan. 2013. Theorising a model for teaching and assessing reflective learning in higher education. Higher Education Research and Development 32(2): 244-257.

Schaub-de Jong, M. A., J. Schönrock-Adema, H. Dekker, M. Verkerk and J. Cohen-Schotanus. 2011. Development of a student rating scale to evaluate teachers' competencies for facilitating reflective learning. Medical Education 45(2): 155-165.

Seckler-Walker, J. and S. Taylor-Adams. 2001. Clinical incident reporting. In Clinical risk management: Enhancing patient safety, ed. C. Vincent. London: BMJ Books.

Sherwood, G. D. and S. Horton-Deutsch. 2012. Reflective practice: Transforming education and improving outcomes. Indianapolis: Sigma Theta Tau International.

Shurville, S. and A. Rospigliosi. 2009. Implementing blended self-managed action learning for digital entrepreneurs in higher education. Action Learning: Research and Practice 4(1): 53-61.

Smith, J. W. and D. K. Stitts. 2013. Using action learning and critical thinking tools to make changes in higher education. Contemporary Issues in Education Research 6(1): 73-83. 
Stage, F. K. and D. Hossler. 2000. Where is the student? Linking student behaviours, college choice, and college persistence. In Reworking the student departure puzzle, ed. John M. Braxton, 170 195. Nashville, TN: Vanderbilt University Press.

Tracy, S. J. 2010. Qualitative quality: Eight "Big-Tent" criteria for excellent qualitative research. Qualitative Inquiry 16(10): 837-851.

Van Beveren, L., G. Roets, A. Buysse and K. Rutten. 2018. We all reflect, but why? A systematic review of the purposes of reflection in higher education in social and behavioral sciences. Educational Research Review 24: 1-9.

Walsh, D. and S. Downe. 2005. Meta-synthesis method for qualitative research: A literature review. Journal of Advanced Nursing 50(2): 204-211. 